\title{
Relationships between RNA content and egg production rate in Acartia bifilosa (Copepoda, Calanoida) of different spatial and temporal origin
}

Towe Holmborn · Elena Gorokhova

Published online: 15 January 2008

(C) Springer-Verlag 2008

Erratum to: Mar Biol (2008) 153:483-491

\section{DOI 10.1007/s00227-007-0838-2}

Unfortunately, the presentation of Table 1, with caption, and the figure caption of Fig. 2 are incorrect. The correct Table 1 and Fig. 2 are given below.
The online version of the original article can be found under doi: 10.1007/s00227-007-0838-2.

T. Holmborn $(\square) \cdot$ E. Gorokhova Department of Systems Ecology, Stockholm University, 10691 Stockholm, Sweden e-mail: towe@ecology.su.se

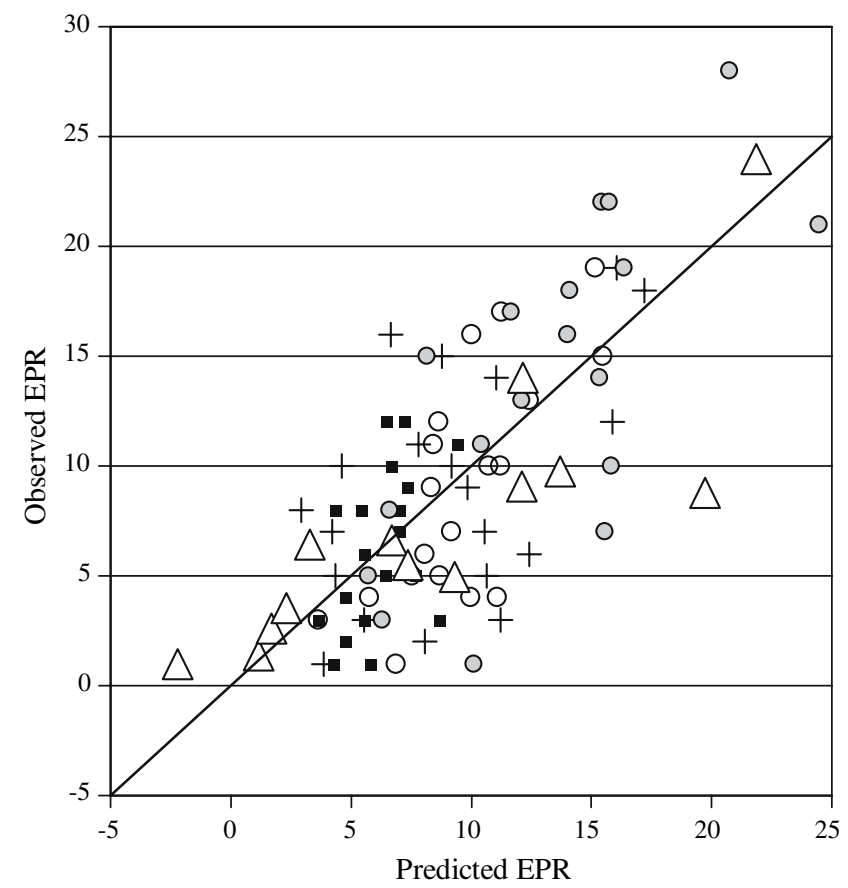

Fig. 2 A. bifilosa. Observed vs. predicted egg production rate $(E P R$, eggs female ${ }^{-1}$ day $^{-1}$ ). The overall correlation is statistically significant (Spearman rank correlation test, $r=0.67, P<0.0001, N=89)$. Study periods: A1 (filled square)—Askö, spring $(N=19)$; A2 (plus sign)— Askö, summer $(N=20)$; T1 (open circle)-Tvärminne, spring $(N=19)$; T2 (filled circle) - Tvärminne, summer $(N=18)$; G2003 (open triangle) — data from Gorokhova $2003(N=13)$ collected in August 1998 east of Gotland $\left(57^{\circ} 36^{\prime} \mathrm{N}, 1^{\circ} 21^{\prime} \mathrm{E}\right.$ and $57^{\circ} 16^{\prime} \mathrm{N}$, $\left.20^{\circ} 05^{\prime} \mathrm{E}\right)$. The predicted values of EPR were calculated using formula: $\mathrm{EPR}=14.74+106.17 \times \mathrm{RNA}-43.79 \times \mathrm{PL}+0.24 \times T$ (Table 1d $).$ The line represents observed $E P R=$ predicted $E P R$ 
Table 1 A. bifilosa: results of multiple linear regression analysis

\begin{tabular}{|c|c|c|c|c|c|c|}
\hline Variable & Beta \pm SE & Partial corr. & $P$ level & $R^{2}$ & Adjust $R^{2}$ & SE estimate \\
\hline $\begin{array}{l}\text { (a) } \mathrm{RNA}=-0.321+0.721 \times \mathrm{PL} \\
+0.003 \times \mathrm{EPR}-0.026 \times \text { season }\end{array}$ & & & & 0.88 & 0.88 & 0.02 \\
\hline Intercept & & & 0.0000 & & & \\
\hline PL & $0.85 \pm 0.06$ & 0.87 & 0.0000 & & & \\
\hline EPR & $0.31 \pm 0.05$ & 0.61 & 0.0000 & & & \\
\hline Season & $-0.20 \pm 0.05$ & -0.42 & 0.0002 & & & \\
\hline $\begin{array}{l}\text { (b) } \mathrm{RNA}=-0.254+0.655 \times \mathrm{PL}+ \\
0.003 \times \mathrm{EPR}-0.002 \times T\end{array}$ & & & & 0.87 & 0.86 & 0.02 \\
\hline Intercept & & & 0.0000 & & & \\
\hline PL & $0.78 \pm 0.05$ & 0.87 & 0.0000 & & & \\
\hline EPR & $0.31 \pm 0.05$ & 0.59 & 0.0000 & & & \\
\hline$T$ & $-0.12 \pm 0.05$ & -0.30 & 0.0087 & & & \\
\hline $\begin{array}{c}\text { (c) } \mathrm{EPR}=24.57+113.05 \times \mathrm{RNA}- \\
56.81 \times \mathrm{PL}+2.98 \times \text { season }\end{array}$ & & & & 0.53 & 0.51 & 4.22 \\
\hline Intercept & & & 0.0052 & & & \\
\hline RNA & $1.21 \pm 0.18$ & 0.61 & 0.0000 & & & \\
\hline PL & $-0.72 \pm 0.21$ & -0.37 & 0.0011 & & & \\
\hline Season & $0.25 \pm 0.11$ & 0.26 & 0.0256 & & & \\
\hline $\begin{aligned}(\mathrm{d}) \mathrm{EPR} & =14.74+106.17 \times \mathrm{RNA}- \\
43.79 & \times \mathrm{PL}+0.24 \times T\end{aligned}$ & & & & 0.51 & 0.49 & 4.30 \\
\hline Intercept & & & 0.0418 & & & \\
\hline RNA & $1.14 \pm 0.18$ & 0.59 & 0.0000 & & & \\
\hline PL & $-0.56 \pm 0.19$ & -0.32 & 0.0049 & & & \\
\hline$T$ & $0.14 \pm 0.09$ & 0.18 & 0.1235 & & & \\
\hline
\end{tabular}

All regressions are significant $(P<0.0001, n=76)$

Four models were tested: (a) $\mathrm{RNA}=b_{0}+b_{1} \mathrm{PL}+b_{2} \mathrm{EPR}+b_{3}$ station $+b_{4}$ season, (b) $\mathrm{RNA}=b_{0}+b_{1} \mathrm{PL}+b_{2} \mathrm{EPR}+b_{3} T,(\mathrm{c}) \mathrm{EPR}=b_{0}+b_{1}$ $\mathrm{RNA}+b_{2} \mathrm{PL}+b_{3}$ station $+b_{4}$ season, and (d) $\mathrm{EPR}=b_{0}+b_{1} \mathrm{RNA}+b_{2} \mathrm{PL}+b_{3} T$. The factors, for which data are presented above, contributed significantly with explanatory values and were selected by forward stepwise selection procedure

$P L$ is prosome length (mm), $R N A$ - RNA content in female ( $\mu$ g RNA female ${ }^{-1}$ ), $E P R$ - egg production rate (eggs female ${ }^{-1}$ day $^{-1}$ ), and $T-$ ambient $^{-}$ surface temperature during sampling $\left({ }^{\circ} \mathrm{C}\right)$. Beta $\pm S E$ is beta weights with standard errors, partial corr - partial correlations, and SE estimate standard error of value estimated from the regression equation 